\title{
Wittgenstein's Theory of Fallacy
}

\author{
S. MORRIS ENGEL University of Southern California
}

1

When Wittgenstein returned to philosophy some ten years after the completion of the Tractatus, what again came to absorb his interest was the very question that he thought he had solved in that earlier work: "How does language come to signify?" In this new period of his thought, however, he came to see that his old conception of language as being a mirror of reality was mistaken. Far from being a mirror whose sole object was to reflect reality, language was a tool capable of many uses. Since the failure to take note of this peculiar feature of language was something he shared with other philosophers, he came to regard this as not only responsible for his own former impasses but also what was at the root of the impasses of his fellow philosophers. And thus was born what he regarded as his new mission: to show others how they too have been misled by language.

What Wittgenstein came to say on this topic in his so-called later works has almost universally been regarded as totally different from what he had said and maintained earlier. But a picture theory lies at the foundation of the later works as well and although it differs in many respects from the earlier picture theory, it nevertheless bears some striking resemblances to it. [1] In addition, and again not unrelated to various strands that run through the Tractatus, its elaborations in the various later writings represent one of the first detailed and sustained discussions in modern times of the theory of fallacy, a theory whose roots too can already be found in the Tractatus. By "theory of fallacy" what I have in mind are his detailed investigations of the sources of "conceptual confusion" - of the way we are led astray by language, as he often puts it; investigations that were far different from the type undertaken before by others (Kant, for example). They were, as I will try to show here, much closer to the type that have become of so much concern to more recent writers.

That Wittgenstein had such a theory, that it was a dominant concern of his in both periods, and that it is not without interest, is what I should like to propose and explain in what follows.

\section{2}

Wittgenstein's interest in "pictures" begins very early. In a brief passage in the Notebooks[2] (dated November 15, 1914) he says: "That shadow which the picture as it were casts upon the world: How am I to get an exact grasp of it? Here is a deep mystery." Turning to this mystery in the Tractatus[3] he says enigmatically at 2.1, "We picture facts to ourselves." "A picture," he adds at 2.12, "is a model of reality." How is this possible? It is possible because, as he puts it, "In a picture objects have the elements of the picture corresponding to them" (2.13); or, put otherwise, "In a picture the elements of the picture are the representatives of objects" (2.131). A picture, he says, "is attached to reality; it reaches right out to it" (2.1511); "it is laid against reality like a ruler" (2.1512).

But how do "pictures" manage to "reach out" in this way and become 
such "models" of reality? He replies that "pictures" are able to do this in virtue of possessing "something in common" with what they depict (2.16 and 2.161), and what they have in common with reality is "logical form" (2.18). Thus, a picture can depict any reality whose form it has. It is this that enables a "proposition," for example, to picture reality, for a proposition is in fact a picture or a model of reality (4.01).

Wittgenstein is quite aware that a proposition (one "set out on the printed page, for example" ) does not at first sight "seem to be a picture of the reality with which it is concerned." "But no more," he adds, "does musical notation at first sight seem to be a picture of music, nor our phonetic notation the alphabet) to be a picture of our speech. And yet these sign-languages prove to be pictures, even in the ordinary sense, of what they represent" (4.011).

One might object that neither music nor the phonetic system even remotely resembles musical sound or speech, but again what he has in mind here is their common formal or logical patterns and not anything strictly pictorial. This seems at least to be indicated by such further remarks as: "It is obvious that a proposition of the form ' $a R b$ ' strikes us as a picture. In this case the sign is obviously a likeness of what is signified" (4.012). "They are all constructed," he remarks again at 4.014, "according to a common logical plan." "That is what constitutes the inner similarity between these things which seem to be constructed in such entirely different ways"' (4.0141).

He notes further that this is what, as a matter of fact, lies behind the possibility "of all imagery, of all our pictorial modes of expression," for logical form is more fundamental and prior to the imagery and the strictly pictorial characteristics. These are, he suggests, a later product and, in a sense, even unnecessary. For, as he says at 4.016, "in order to understand the essential nature of a proposition we should consider hieroglyphic script, which depicts facts that it describes. And alphabetic script developed out of it without losing what was essential to depiction." What, in short, that is to say, enables hieroglyphics - and by extension, our alphabet-to function in the way they do is not anything pictorial or iconic about them but rather the logical patterns they inscribe for us.

It has sometimes been objected that while it may be true that propositions may "refer" to reality, "state" things about it, "describe" it, and so on, it cannot, strictly speaking, be said, as Wittgenstein seems to be saying, that they represent or picture it. But to criticize Wittgenstein in this way is to misunderstand his point here. What, according to him, permits the proposition to "picture" the facts it describes is the logical structure it shares with them, and not anything sensual, which it obviously does not possess in common with them. Propositions, that is to say, can picture facts not because they are identical with them but rather because they are structurally similar with them.

What perhaps has tended to mislead readers is that they have thought Wittgenstein was speaking here about the way ordinary sentences picture ordinary, everyday objects, whereas what Wittgenstein seems to be concerned with are not ordinary sentences and ordinary, everyday objects, but rather unordinary, primitive or elementary propositions and the way these depict what he calls states of aftairs.

If it is indeed true that what is involved here are not ordinary sentences but something bordering on the conceptual (that is, "states of affairs"), then to say the one "pictures" the other is not any longer to say anything very startling. For the "picturing"' here, far from representing or applying anything like a mirror image, implies something far different from it. That this must be so seems to be clear from his reference to hieroglyphic script. For, after all, even hieroglyphic script does not in any ordinary sense "depict the facts that it describes." If it did even a child would be able to decipher it. Yet he describes this as a "depiction."

Wittgenstein is still dealing here in 
the main with matters that are far removed from ordinary or familiar events, and the mirror images in which we tend on that plane occasionally to conceive them. Not that these "pictures," as he is quick to point out, are always "completely congruent with the concept" they are designed to depict. On the contrary, that is precisely how confusions arise. For, according to Wittgenstein, they arise from the fact "that the apparent logical form of a proposition," as already pointed out by Russell, "need not be its real one" (4.0031).

But, more interestingly from our point of view, confusion may also arise, from the nature of the sign system we employ (or from the nature, as he will later call it, of our "notation"). "A sign," he explains in Tractatus 3.32, "is what can be perceived of a symbol." But one and the same sign can be common to two different symbols, as is often the case in our language. No harm is done as long as we realize they are signifying two quite different things, and really therefore belong to two different symbols. But this is not always the case. "In the proposition, 'Green is green,' "' for example, "where the first word is the proper name of a person and the last an adjective-these words do not merely have different meanings: they are different symbols" (3.323). This is, of course, an example not likely to mislead anyone. It is, however, in this way that "the most fundamental confusions are easily produced (the whole of philosophy is full of them)" (3.324).

In order to avoid such errors,' Wittgenstein concludes, "we must make use of a sign-language that excludes them by not using the same sign for symbols and by not using in a superficially similar way signs that have different modes of signification: that is to say, a sign-language that is governed by logical grammar-by logical syntax" (3.325).

These highly suggestive remarks regarding the ideographic or linguistic origin of conceptual confusion are left undeveloped in the Tractatus. In that work his main interest is to unravel the bare, abstract structure of the world as "pictured" in our ideography. When he returns to the task some ten years later, what comes to interest him a good deal more, as we will soon see, is the nature of this ideography itself. What emerges as a result is a vastly more detailed theory of the origin of conceptual and linguistic confusion and the tyranny of words.

In the early work the dominant interest is not to explain how propositions fail to signify but what makes it possible for them to do so. And what makes it possible for them to do so is, as we have seen, the common logical form they share with what they depict. But how can we ever be sure that they do so depict it? Can we step out of language in order to compare the two? Wittgenstein's answer to this question is, of course, both famous and mysterious. "In order to be able to represent logical form," he says, "we should have to be able to station ourselves with propositions somewhere outside logic, that is to say outside the world" (4.12), and, of course, we cannot do that. And we cannot do that, for, again "what finds its reflection in language, language cannot represent. What expresses itself in language, we cannot express by means of language" (4.121). But this, he says, does not mean that we are entirely trapped in language. What cannot be said, can yet be shown. Thus it is that while it is true that a picture cannot depict its pictorial form, it can yet display it (2.172). And similarly with propositions: while it is true that they cannot represent logical form, this does not prevent them from mirroring it (4.121). "There are, indeed," as he reassures the reader towards the end of the Tractatus, "things that cannot be put into words" (6.522), "They make themselves manifest; they are, he ends by saying, "what is mystical."

What distinguishes the later works from the early (the Notebooks and 
Tractatus) is Wittgenstein's determination to deal with the surface grammar of words, with what words say rather than with what they manifest, for the traps at that level can be just as treacherous as those at the deeper levelsregarding which, in any case, nothing more can be said. Thus although the picture theory that gradually emerges in these new works is, like the one found in the Tractatus, designed to show us how we become trapped in language, unlike the Tractatus theory, the traps are conceived not as ontological ones, but rather as developmental ones; that is, they are traps we can free ourselves from, given the proper insights. All involve becoming aware of certain peculiarities of language. Together they constitute, as said earlier, a substantial theory of the sources of conceptual confusion, a theory, in effect, of fallacy. The first of these has to do with the nature of words; the second, with the nature of sentences; and the third, with certain aspects of our psychology.

What particularly struck Wittgenstein now about words was that despite the numerous and diverse roles they play, the mental images they generate do not always keep up with the new usages but tend to lag behind them. And it is the same with the sentences we form with these words: while the facts of our experience are unlimited and enormously varied, the forms of language, or sentence structures with which we are compelled to describe and record them are few in number. The dangers of misdescribing and misrecording these facts are thus unlimited. What, finally, feed and are in turn fed by these tendencies towards economy in language are our own mental attitudes, which strive always towards unity, simplicity, and economy. And this too tends to do violence to the multifarious nature of our experience.

Mainly, however, what he came to see at this point in his thinking was that a different, more literal, sort of "picturing" seems to take place in language, one which, more than anything else, seems to be responsible for our philosophic puzzlement and confusion. What this is may be gathered from a rather striking example recounted by Professor Norman Malcolm in his Memoir of Wittgenstein:

At one of the at-homes, Wittgenstein related a riddle for the purpose of throwing some light on the nature of philosophy. It went as follows: Suppose that a cord was stretched tightly around the earth at the equator. Now suppose that a piece one yard long was added to the cord. If the cord was kept taut and circular in form, how much above the surface of the earth would it be? Without stopping to work it out, everyone present was inclined to say that the distance of the cord from the surface of the earth would be so minute that it would be imperceptible. But this is wrong. The actual distance would be nearly six inches. Wittgenstein declared that this is the kind of mistake that occurs in philosophy. It consists in being misled by a picture. In the riddle the picture that misleads us is the comparison of the length of the additional piece with the length of the whole cord. The picture itself is correct enough: for a piece one yard long would be an insignificant fraction of the length of the whole cord. But we are misled by it to draw a wrong conclusion. A similar thing happens in philosophy: we are constantly deceived by mental pictures which are in themselves correct.[4]

According to Wittgenstein these "pictures" generated by the way we speak have an especially strong tendency to mislead the nonprofessional and the philosopher anxious to understand the work and contributions of the various new discoveries and inventions - the nonmathematicians, for example, whose interest in the work of the mathematician stems, initially, not from anything internal or directly relevant to these investigations but rather from the associations these expressions tend to arouse in their minds. What fascinates them are the pictures the mathematician's talk about his work tends to conjure up. And these pictures are misleading: they tend to make his work seem more important and more glamorous than it would 
otherwise seem to be. This may not be a bad thing, for without such glamor no one might have become interested in these problems to begin with; they are, however, not what the problems, once begun, are really about.

In order to understand a word, says Wittgenstein,[5] we must know its use. With a great many words a certain picture represents for us both its meaning and its use. This is the case, for example, with the word "chair." One of the great benefits this tendency of words to arouse pictures of what they represent has, is that it guarantees that we will all use these words in the same way. In other cases, however, these pictures are very misleading. An example here is the word "particle," which, unfortunately, is no longer used in such a way that the picture has any use. For rather than guaranteeing that we will use the word in similar ways, such new uses to which old words are put tend rather to have the reverse effect. And this will be so whenever the words in question no longer continue to be used by us in their ordinary and familiar ways. Then the words are misleading - understandably so, for the pictures they create lead us to expect the wrong things and with obvious results.

But that is not all. For a curious by-product of this tendency to continue to apply standard pictures in situations where they are no longer really appropriate is the sense of amazement this often generates. Thus, for example, thinking of the formula "the cardinal number of all cardinal numbers" in terms of, say, "chairs" has a kind of dizzying effect on the mind, for the number involved is truly staggering. It conjures up, he says, "a picture of an enormous colossal number. And this picture has a charm." But the imagery here, although a natural and understandable consequence of our tendency to assimilate and correlate various expressions in our language, is entirely inappropriate. For in fact, we have as yet, as he puts it, "no right to have an image. The imagery is connected with a different calculus:
$30 \times 30=900^{\prime \prime}$ (Math Notes). It is the same in many other cases: the sense of amazement and puzzlement experienced at such occasions is simply a product of a misapplied image.

On the contrary, we may go even further than that. If something about a certain subject or problem "charms or astounds" us, we may conclude from this that it is because we have been captivated by "the wrong imagery." Imagery of that sort is a function of metaphors and such metaphors remain "fishy" as long as they are "exciting." When we begin to see these things in their true light, the amazement and excitement simply vanish. Thus, for example, certain parts of mathematics are regarded as "deep." "But the apparent depth comes from a wrong imagery. It is pedestrian as any calculus" (Math Notes). Yet that is precisely the way people were misled about the infinitesimal calculus when they mistakenly believed that it treated of infinitely small quantities. It is because we think of such things in terms of such misleading images (for example, in terms of sizes, as here) that we go wrong. The amazement and excitement such things inspire in us should be taken as a sign that we have simply been misled.

Wittgenstein speaks in these mathematical writings of "charm," "excitement," "amazement," and so on, but it is easy to see how these expressions give way in the other works to such more familiar ones as "puzzlement," "wonder," and "confusion." That transition is to be found, in fact, in these writings themselves. He remarks, for example:

There is one kind of misunderstanding which has a kind of charm... we say that the line intersects at an imaginary point. This sets the mind in a whirl, and gives a pleasant feeling of paradox, e.g. saying that there are numbers bigger than infinity.... He has employed a sensational way of expressing what he has discovered, so that it looks like a different kind of discovery. ...he describes a new state of affairs in old words, and so we don't understand him. The picture 
he makes does not lead us on. By the words of ordinary language we conjure up a familiar picture-but we need more than the right picture, we need to know the correct use.[6]

And this is precisely where such new notations, he emphasizes here, fail us so badly. The fact is that "in an overwhelming number of cases people do have the same sort of images suggested by words. This is a mere matter of fact about what happens in our minds, but a fact of enormous importance" (Math Notes). In view of this, it is not difficult to see why and how confusions arise. For all that is really necessary for this to happen is for us to use familiar words in unfamiliar ways. The pictures aroused will be correct enough but, of course, they will be misleading. And it is in such misleading pictures, he concludes here as well, "that most of the problems of philosophy arise" (Math Notes).

We have here a much more complicated and detailed account of the genesis of linguistic confusion than in the Tractatus. Wittgenstein now sees that it is not simply the fact that the same words can stand for different things ("Green is green") that is responsible for confusion; it is the images that words create in our minds and the way these images fail to keep up or fail to be congruent with changing usage that is the real culprit. And such images, he now sees, by failing to be so congruent with the states of affairs they describe, sometimes have the effect of sensationalizing those affairs and hence of distorting them even further.

As a theory of fallacy, as I take it to be, this does indeed seem more promising. For while the account as left in the Tractatus may perhaps be sufficient to explain such strictly linguistic or ideographic confusions (or fallacies) as "Green is green" or, to use a rather more interesting example, such an argument as:

(a) If you believe in the miracles of science, why not in the miracles of the Bible?

it cannot do justice to the more com - plicated examples found both in philosophic literature and in the daily press.

Consider, for example, the following famous passage or argument from the second chapter of Locke's Essay regarding innate ideas:

(b) For first, it is evident that all children and idiots have not the least apprehension or thought of them; and the want of that is enough to destroy that universal assent which must needs be the necessary concomitant of all innate truths: it seeming to me near a contradiction to say that there are truths imprinted on the soul which it perceives or understands not: imprinting, if it signify anything, being nothing else but the making certain truths to be perceived. For to imprint anything on the mind without the mind's perceiving it, seems to me hardly intelligible. If therefore children and idiots have souls, have minds, with those impressions upon them, they must unavoidably perceive them, and necessarily know and assent to these truths; which since they do not, it is evident that there are no such impressions... He therefore that talks of innate notions in the understanding, cannot (if he intend thereby any distinct sort of truths) mean such truths to be in the understanding as it never perceived, and is yet wholly ignorant of. For if these words (to be in the understanding) have any propriety, they signify to be understood, so that to be in the understanding and not to be understood, to be in the mind and never to be perceived, is all one as to say anything is and is not in the mind or understanding. [7]

Locke's argument here against innate ideas seems fallacious, turning on the equivocal use of the terms "to be in the understanding" and "imprint." For the supporters of innate ideas did not intend the term "to be in the understanding," or the term "imprint" to mean, as he seems to like to think they did, that these truths were to be found full-blown in the understanding (even in the understanding of a child or idiot) but merely that the normal understanding had the capacity to achieve them. And if so they were not necessarily guilty of contradicting themselves in believing that something 
could be "in" the understanding without the person being explicitly aware of it. It is therefore curious that Locke came to think otherwise.

Wittgenstein's account of the way the old images generated by our words often daze and startle the mind when applied to new situations to which they are no longer appropriate and which they consequently misrepresent, helps explain how Locke might have come to do so; how momentarily indeed he might have been taken in by his manner of expressing himself in maintaining what he does in that passage. Wittgenstein's account helps us see that Locke is neither being sophistical nor sarcastic; on the contrary, that again we have here a case where a person's mind, by being held captive by an "image," - the image here of something being literally "in" something else, or being literally imprinted on something-becomes disoriented and confused and falls victim to a fallacy. We might say that in a sense Locke is here the "nonprofessional," trying to deal with a proposed new and possibly novel idea-innate ideasin words whose old images inevitably distort and misrepresent it for him. He is the man in the street, talking about a new scientific discovery in everyday language and being startled by the results.

This phenomenon is easier to detect in those cases where the language employed is somewhat more "sensational" than that generally typical of scholarly writing. Consider, for example, the following editorial from Spotlight:

(c) I am puzzled by the protest groups that gather in front of prisons when an execution is scheduled. The murderer, who has committed a heinous crime, has been granted all due process of law and is given every opportunity to defend himself-usually with the best available legal minds and often at taxpayers' expense. Yet these same protestors generally favor the execution of millions of innocent babies by abortion. [8]

Although here too it may be somewhat difficult to believe that the writer of this editorial could have been unaware of the fallacy he was committing, unaware of the point, that is, that since the women alluded to would not regard a fetus as a human being (and if he would insist that it is, they would be right in charging him with begging the question), they would not regard themselves as being inconsistent in being in favor of terminating the one kind of "life" and not the other, it is not difficult to see how his readers might fail to do so; employing - to use Wittgenstein's words again-"'a sensational way of expressing what he has discovered," the writer deceives his readers by making it "look like a different kind of discovery," - namely, that being in favor of aborting a fetus, the women in question are in favor of "executing innocent babies" (and being perverse, to boot, in being opposed to "executing murderers"). We have here a clear and striking example of that situation, commented on by Wittgenstein, of the nonprofessional trying to deal with a professional (i.e. a technical or scientific) issue in words whose images inevitably distort and misrepresent it. Wittgenstein's account of these kinds of confusion and puzzlement makes it clearer not only why such arguments deceive but why they have the force they do.

Interestingly enough we occasionally meet with the reverse phenomenon: professionals attempting to persuade (or perhaps even deceive) nonprofessionals by a reverse type of distortion. The following somewhat lengthy Monsanto advertisement concerning the dangers of chemicals is a case in point:

\section{(d) MOTHER NATURE IS LUCKY HER PRODUCTS DON'T NEED LABELS}

(Ad shows a picture of a hand holding a fresh orange)

All foods, even natural ones, are made up of chemicals. But natural foods don't have to list their ingredients. So it's often assumed they're chemicalfree. In fact, the ordinary orange is a miniature chemical factory. And the good old potato contains arsenic among 
its more than 150 ingredients. This doesn't mean natural foods are dangerous. If they were, they wouldn't be on the market. The same is true of manmade foods. All man-made foods are tested for safety. And they often provide more nutrition, at a lower cost, than natural foods. They even use many of the same chemical ingredients. So you see, there really isn't much difference between foods made by Mother Nature and those made by man. What's artificial is the line drawn between them.

\section{MONSANTO...WITHOUT CHEMI- CALS LIFE ITSELF WOULD BE IMPOSSIBLE}

What is interesting about this advertisement is its clever attempt to remove the bad connotation surrounding the word "chemical" so that the reader will come to believe that man-made products and the chemicals that go into them are no different from and are just as safe as nature's products and the chemicals that nature puts into them. It tries to achieve this first by associating that normally somewhat frightening word with the neutral term "ingredients," and then very soon after by combining it with the former and speaking of "chemical ingredients." Having performed this bit of sleight-of-hand, the writer feels confident enough to conclude by assuring the reader that "there isn't much difference between foods made by Mother Nature and those made by man" - what both put in them are, after all, only "ingredients." And so chemicals have become ingredients and just as harmless as them-all accomplished in this case by reversing the process, by desensationalizing something that is normally (and probably quite correctly) conceived in sensational terms.

\section{4}

On one level, as we have seen, arguments like those just examined turn on the equivocal use of a term or phrase (on "miracles," in that brief argument, or on the phrase "in the understand- ing," in the argument from Locke's Essay, or on "execution," in the argument from Spotlight, and so on). Wittgenstein recognized, however, that such arguments can also be seen as attempts to draw analogies between different cases-and with the same results. What he says about such analogies is enormously interesting. However, although not unmindful of the role which the image-generating capacity of words play in the new confusions he is about to examine, what now mainly comes to absorb his attention are the confusions whose source lies in our misunderstanding of what he now calls the "grammar" of words.

A good example of this new type of confusion can be found in his discussion of the ancient problem regarding the nature of time. Having tried to solve this problem in the way we might try, by analogy, to solve the problem of the ultimate constituents of matter and not succeeding very well, we tend to think that these philosophical entities are very queer things, and very difficult to get at.
We are...tempted to think that here are things hidden, something we can see from the outside but which we can't look into. And yet nothing of the sort is the case. It is not new facts about time which we want to know. All the facts that concern us lie open before us. (Blue
Book, p. 6)

But it is the use of the noun "time" and the form in which we pose this question that misleads us into dealing with it in an impossible way. If we would look into the "grammar" of that word we would no longer be puzzled and would know quite well how to use it. And that is all we mean by it.

But unfortunately the question, "What is Time?" which so puzzled Saint Augustine, like ordinary scientific questions appears to ask for something else-for some factual information-and this leads us to deal with it as if it were indeed an ordinary scientific or empirical question. But this is wrong and not what is wanted 
here. We do not see this because the puzzlement expresses itself here in a misleading way by means of the form of the question "What is...?" But this is simply, in this case, an utterance of "unclarity, of mental discomfort... comparable with the question 'Why?' as children so often ask it" - a question that like "What is..?" "doesn't necessarily ask for either a cause or a reason," but is simply an expression of puzzlement (Blue Book, p. 26).

It is little wonder, therefore, that such questions cannot be answered by providing information but only by coming to recognize their cause, which lies in certain "contradictions" in the grammar of the words used. "Augustine, we might say, thinks of the process of measuring a length: say, the distance between two marks on a travelling band which passes us, and of which we can only see a tiny bit (the present) in front of us" (Blue Book, p. 26). Thinking of time in terms of such an analogy-of such a picture embedded in the notion of "measuring" common to the two cases-he naturally became puzzled as to how it could be done; how, that is, it should be possible for one to be able to measure it. For the past, as he himself put it, can't be measured, as it is gone by; and the future can't be measured because it has not yet come; and, finally, the present can't be measured, for it has no extension. What, then, is time?

If time were indeed like such a passing band (the part that is to be measured not having arrived yet and the other part already gone by), we would certainly not be able to measure it by laying, say, a ruler alonside it. To solve this puzzle, what we must therefore do is to come to see that we mean quite a different thing by "measurement" when applied to a band continuously passing by us and when applied to such a thing as time. It is because we try to apply such words rigidly and consistently and find that we cannot, that we run into difficulties and become bewildered. We fail to see that we are really victims here of a kind of equivocation, that the same word may have quite different meanings when used in different contexts. "The problem may seem simple, but its extreme difficulty is due to the fascination which the analogy between two similar structures in our language can exert on us" (Blue Book, p. 26). Like children, we-that is, those who are thus perplexed - find it hard to believe that one word can have two meanings.

Wittgenstein goes on to generalize this point. "Philosophy, as we use the word, is a fight," he says, "against the fascination which forms of expression exert upon us" (Blue Book, p. 27). It is an attempt "to counteract the misleading effect of certain analogies" (Blue Book, p. 28). "The man who is philosophically puzzled sees a law in the way a word is used, and, trying to apply this law consistently, comes up against cases where it leads to paradoxical results" (Blue Book, p. 27). What we must try to do is to undermine and loosen this rigidity of mind and counteract the effect these misleading analogies have upon us.

Two aspects of Wittgenstein's analysis here are important. The first is his view, apparently, that what makes us particularly prone to these pitfalls in language is a certain mental rigidity. If we have come to understand a term in a certain way, we have a tendency to continue to understand it that way, come what may. Unfortunately for us (and here we come to Wittgenstein's second point), a certain feature of language tends to collaborate to sustain this mental rigidity. This feature is the highly analogical character of language, which tends to lull us into thinking that there is more unity and uniformity in the facts recorded than there really is. Wittgenstein never tires of emphasizing the hypnotic effect this feature of language has on us. "We aren't able to rid ourselves of the implications of our symbolism" (Brown Book, p. 108), he says at one place. "We are led into puzzlement by an analogy which irresistibly drags 
us on" (ibid.). Or again: "A picture held us captive. We could not get outside it, for it lay in our language and language seemed to repeat it to us inexorably" (Philosophical Investigations I, 115). [9]

Wittgenstein doesn't want to claim that all analogies necessarily lead to the kind of confusion he describes here, nor that all analogical thinking is bad. There are no doubt many analogies that are, from this point of view, entirely harmless, and many that are extremely useful.

\begin{abstract}
When we say that by our method we try to counteract the misleading effect of certain analogies, it is important that you should understand that the idea of an analogy being misleading is nothing sharply defined. No sharp boundary can be drawn round the cases in which we should say that a man was misled by an analogy. The use of expressions constructed on analogical patterns stressed analogies between cases often far apart. And by doing this these expressions may be extremely useful. It is, in most cases, impossible to show an exact point where an analogy begins to mislead us. Every particular notation stresses some particular point of view. (Blue Book, p. 28)
\end{abstract}

"The cases," however, "in which particularly we wish to say that someone is misled by a form of expression are those in which we would say: 'He wouldn't talk as he does if he were aware of this difference in the grammar of such-and-such words, or if he were aware of this other possibility of expression' and so on" (lbid.).

To make this point clearer Wittgenstein draws our attention to a host of different examples.

It might be found practical to call a certain state of decay in a tooth, not accompanied by what we commonly call toothache, "unconscious toothache" and to use in such a case the expression that we have toothache, but don't know it. It is just in this sense that psychoanalysis talks of unconscious thoughts, acts of volition, etc. Now is it wrong in this sense to say that I have toothache but don't know it? There is nothing wrong about it, as it is just a new terminology and can at any time be translated into ordinary language. On the other hand it obviously makes use of the word "to know" in a new way (ibid., pp. 22-23).

But unfortunately the new expression not only leads us to think that we have done more than we actually have but it also calls up for us "pictures and analogies which make it extremely difficult for us to go through with our conventions" (ibid., p. 25). And this in turn creates puzzlement and gives rise to bad philosophy.

Thus, by the expression ' unconscious toothache," for example, we are:

\begin{abstract}
Misled into thinking that a stupendous discovery has been made, a discovery which in a sense altogether bewilders our understanding; or else you may be extremely puzzled by the expression (the puzzlement of philosophy) and perhaps ask such a question as "How is unconscious toothache possible?" You may then be tempted to deny the possibility of unconscious toothache; but the scientist will tell you that it is a proved fact that there is such a thing, and will say it like a man who is destroying a common prejudice. He will say: "Surely it's quite simple; there are other things which you don't know of and there can also be toothache which you don't know of. It is just a new discovery." You won't be satisfied, but you won't know what to answer (ibid., p. 23).
\end{abstract}

But what has been overlooked by these disputants is, inter alia, the fact that these other things we "don't know of" are things which, unlike having a toothache, we "don't have." And what puzzles us is the fact that since a toothache is something "we have," we ought, normally speaking, "know of it." The new notation, although not unintelligible, does not seem to provide room for this, and thus runs into conflict with the old. This generates confusion and puzzlement.

All these remarks apply beautifully, of course, to the passage from Locke discussed above. Locke believes the proponents of innate ideas are claiming to have made an astounding discovery 
- namely, the existence of ideas imprinted from birth on in our understanding. But if that is truly so, he cannot understand why children and idiots are not aware of them, or, as he puts it, do not "perceive" them. For how could something "be in the understanding and not be understood"? Locke's puzzlement arises, then, from his failure to realize that the phrase "in the understanding" and the word "imprint" do not mean what he takes them to mean and therefore do not entail the astounding discoveries he believes they do.

It is the same, Wittgenstein goes on to point out, with the so-called "discoveries" of psychoanalysis and all the disputes and confusion this has caused. "Can we have unconscious thoughts, unconscious feelings, etc?" The idea that we can has revolted many people. Others again have said that these were wrong in supposing that there could only be conscious thoughts, and that psychoanalysis had discovered unconscious ones" (Blue Book, p. 57). Both, however, were confused about what had really happened.

The objectors to unconscious thought did not see that they were not objecting to the newly discovered psychological reactions, but to the way in which they were described. The psychoanalysts on the other hand were misled by their own way of expression into thinking that they had done more than discover new psychological reactions; that they had, in a sense, discovered conscious thoughts which were unconscious. The first could have stated their objection by saying "We don't wish to use the phrase 'unconscious thoughts'; we wish to reserve the word 'thought' for what you call 'conscious thought.' ", They state their case wrongly when they say: "There can only be conscious thoughts and no unconscious ones." For if they don't wish to talk of "unconscious thought" they should not use the phrase "conscious thought," either (Blue Book, pp. 57-58).

These disputes and difficulties can be cleared up by recognizing that they are essentially verbal, that what is being disputed are not the facts of the casewhatever those may be-but simply their description.

That this third, more generalized view of the way we are misled is intimately connected with the second view concerning the image-generating capacity of language, is clear from numerous other passages scattered throughout Wittgenstein's writings, where both views seem to exist side by side. Let me illustrate this with one or two examples.

"The new expression misleads us," he says in the Blue Book, "by calling up pictures and analogies which make it difficult for us to go through with our conventions. And it is extremely difficult to discard these pictures unless we are constantly watchful" (p. 23). Now we can be so watchful, he goes on, by asking ourselves at such times "How far does the analogy between these uses go?" We can also try to construct "new notations, in order to break the spell of those which we are accustomed to." In view of what we have seen Wittgenstein say about "pictures," we can perhaps now understand, much better than was possible before, the deeper implications of these remarks: why, for example, he should say that it is extremely difficult to discard these pictures (for they are deeply imbedded in language and generated by it); how being watchful in the way he suggests will enable us to do so (for the realization that language inexorably repeats these images to us cannot help but weaken their effect on us); and why he should speak of the whole process in the terms he does ("go through with our conventions," "spell," "notation," and so forth). The same may be said of a good many other passages in the Blue Book.

Although such discussions tend to be more puzzling without these further aids, occasionally they are, as we now see, surprisingly explicit and clear. Wittgenstein's remark on page 43 of the Blue Book is a case in point. "The scrutiny of the grammar of a word," he says there, summarizing his results, "weakens the position of certain fixed standards of our expression which had 
prevented us from seeing facts with unbiased eyes. Our investigation tried to remove this bias, which forces us to think that the facts must conform to certain pictures embedded in our language."

Such pictures, he warns the reader in the Philosophical Investigations, are often "only like an illustration to a story" and from it alone it is mostly impossible "to conclude anything at all" - for only "when one knows the story does one know the significance of the picture $^{\prime \prime}(1,663)$. But mainly, of course, the trouble with such pictures is that they seem "to fix the sense unambiguously" when this is not at all the case. On the contrary, "the actual use, compared with that suggested by the picture," is "muddied" $(1,426)$.

Certainly language has this effect on us - "the picture is there"; nor need we necessarily dispute its "validity in any particular case." But we do "want to understand the application of the picture" (1, 423). And not only is this often lacking, but other pernicious effects result as well. Or, as he puts it later:

What this language primarily describes is a picture. What is to be done with the picture, how it is to be used, is still obscure. Quite clearly, however, it must be explored if we want to understand the sense of what we are saying. But the picture seems to spare us this work: it already points to a particular use. This is how it takes us in. (II, vii)

In order to save ourselves from being taken in, we ought always to ask: does reality accord with such pictures? (1, 352). These pictures seem "to determine what we have to do, what to look for, and how," but they do not do so. They seem "to make the sense of the expression unmistakable" but in fact prove to be utterly misleading $(1,352)$. For example, "what am I believing in when I believe that men have souls? What am I believing in, when I believe that this substance contains two carbon rings? In both there is a picture in the foreground, but the sense lies far in the background; that is, the application of the picture is not easy to survey" (1, 422). In ordinary circumstances such words and the pictures they generate "have an application with which we are familiar. - But if we suppose a case in which this application is absent we become as it were conscious for the first time of the nakedness of the words and the picture" $(1,349)$, of how "idle" such pictures are $(1,291)$. In the end we must simply regard them as "illustrated turns of speech" $(1,295)$, which stand "in the way of our seeing the use of the word as it is" $(1,305)$

\section{5}

These impressive and intriguing comments concerning language are in the main designed by Wittgenstein to explain the nature, not of fallacy as such, but of philosophical puzzlement. But, as we have also seen, many of them deal with the puzzles and quandries of mathematics, theology, psychoanalysis - to name only a few of the disciplines which come under consideration in Wittgenstein's writings - so it cannot be the case that Wittgenstein meant them to be applied so narrowly.

More accurately, what we might say is that these comments are designated to unravel the phenomenon of conceptual puzzlement or bafflement and to explain why it arises when it does. What Wittgenstein seems to have discovered is that it arises whenever one attempts to say something novel or interesting about a thing or discovery one has made and uses the old words and expressions of our language to do so. What happens at such times is that the images projected by these old words bias the mind and obscure and distort the new or novel thing one is struggling to express or make intelligible to oneself.

In what has preceded I have tried to show how very illuminating it is to approach fallacies from this point of view. Like the startled and puzzled philosopher, wondering, for example, how time could be measured, I have been 
ying to suggest that a person who has ommitted a fallacy is one who has run to a similar sort of contradiction and i baffled: (a) if you believe in the mirales of science, such a person wonders, hy not then in the miracles of the $\mathrm{Bi}$ le? or he wonders how (b) one can be gainst executing murderers but not nnocent babies? or (c) how something an be in the understanding and not be inderstood? or (d) how one can be oprosed to one sort of chemical but not to inother, and so on.

Wittgenstein also suggests, as we lave seen, that such puzzlement arises rom a kind of ignorance: ignorance of he true nature of the thing under exanination, of how it differs from the old, despite its many similarities to it, of now its subtleties and special nuances distinguishes it from the old, which, all the same, it resembles-subtleties and nuances that the professional person alone is aware of and understands but which generally escape the nonprofessional who lacks the knowledge and training. And all this, too, is highly illustrative-nay, we might almost say, definitive - of the common fallacies.

For, again, it is the careless use of the term 'miracle' by supposed professionals (either physicians or their pressagents) which leads the person with the Bible tract under his arm to wonder why such people can believe in the one kind of miracle but not in the other. And similarly with the Editor of Spotlight: averse to opening his mind to the nuances and differences between aborting a fetus and executing a person, he finds himself puzzled how these people can be opposed to the taking of one kind of life but not to the other. And Locke, too, seems, in the passage quoted, obstinate: resisting the subtleties and technicalities entailed in the opposition's claim, he finds himself puzzled how something could be in the understanding and yet not be understood. And, finally, in the Monsanto advertisement we have the phenomenon of the professional trying to make the nonprofessional even less so. The man in the street knows what a chemical is but Monsanto hopes he will come to believe that it is only an "ingredient" and therefore no different than the ingredient Nature puts into her productsand consequently just as safe as they are.

This, then, is Wittgenstein's account of how such puzzlement arises and his answer as to why it strikes so often. In the end, his answer, although insightful and multi-faceted, is in essence not very different from the answer he gave his sister when she wondered how someone so gifted and brilliant as he could decide, as he did soon after World War I, to abandon philosophy and become an elementary school teacher. He replied:
You remind me of someone who is looking through a closed window and cannot explain to himself the strange movements of a passerby. He doesn't know what kind of a storm is raging outside and that this person is perhaps only with great effort keeping himself on his feet.[10]

Wittgenstein spent a good part of his philosophic life peering at that window. We have examined here that portion of it that relates to the theory of fallacy. [11]

\section{Notes}

[1] The view regarding the continuity of Wittgenstein's picture theory taken here is not uncontroversial. For a more detailed defense of it see my book Wittgenstein's Doctrine of the Tyranny of Language (The Hague: Martinus Nijhoff, 1971). For a contrary view see Erik Stenius: "The Picture Theory and Wittgenstein's Later Attitude to it," in Perspective on the Philosophy of Wittgenstein. Edited by Irving Block. (Oxford: Basil Blackwell, 1981).

[2] L. Wittgenstein. Notebooks 1914-1916. Edited by G. H. von Wright and G. E. M. Anscombe with an English translation by G. E. M. Anscombe (Oxford: Basil Blackwell, 1961), p. 30e. 
[3] L. Wittgenstein. Tractatus LogicoPhilosophicus. Translated by D. F. Pears and B. F. McGuinness and with the Introduction by Bertrand Russell. (London: Routledge \& Kegan Paul, 1961).

[4] Norman Malcolm. Ludwig Wittgenstein: A Memoir. With a Biographical Sketch by G. H. von Wright. (London: Oxford University Press, 1958), pp. 53-54.

[5] My account in the next several paragraphs is based mainly upon Malcolm's notes of Wittgenstein's lectures, published without his authorization in San Francisco, Calif., 1954 under the title Math Notes.

[6] Ibid., p. 6

[7] Book 1, Chapter II, Sec. 5.
[8] The Spotlight. Published by Liberty Lobby. July 16, 1979, p. 27.

[9] L. Wittgenstein. Philosophical Investigations. Translated by G. E. M. Anscombe. (Oxford: Blackwell, 1963).

[10] Hermine Wittgenstein. "My Brother Ludwig," in Ludwig Wittgenstein: Personal Recollections. Edited by Rush Rhees. (Oxford: Blackwell, 1981), p. 5.

[11] This paper has benefited greatly from the many improvements suggested by the editors and their reviewers. I am deeply grateful to them for this.

Prof. S. Morris Engel, School of Philosophy, University of Southern California, 3709 Trousdale Parkway, Los Angeles, CA 90089-0451. 